Health Physics Society

8 th Annual Meeting

New York, New York

June 10-13, 1963

MEASUREMENT OF RADTOIODINE

IN PUREX STACK GASES

\author{
W. R. Jacobsen \\ L. Jolly, Jr. \\ Savannah River Plant \\ E. I. du Pont de Nemours and Company \\ Aiken, South Carolina
}

May 1963

To be presented at the Health Physics Society

Annual Meeting in New York City, June 1963

Publisher is requested to include this acknowledgment.

The Information in this article was developed during the course of work under contract AT(07-2)-1 with the U. S. Atomic Energy Commission.

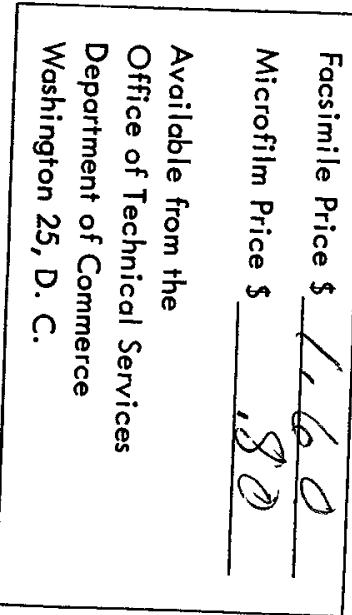




\section{DISCLAIMER}

This report was prepared as an account of work sponsored by an agency of the United States Government. Neither the United States Government nor any agency Thereof, nor any of their employees, makes any warranty, express or implied, or assumes any legal liability or responsibility for the accuracy, completeness, or usefulness of any information, apparatus, product, or process disclosed, or represents that its use would not infringe privately owned rights. Reference herein to any specific commercial product, process, or service by trade name, trademark, manufacturer, or otherwise does not necessarily constitute or imply its endorsement, recommendation, or favoring by the United States Government or any agency thereof. The views and opinions of authors expressed herein do not necessarily state or reflect those of the United States Government or any agency thereof. 


\section{DISCLAIMER}

Portions of this document may be illegible in electronic image products. Images are produced from the best available original document. 


\title{
MEASUREMENT OF RADIOIODINE IN PUREX STACK GASES
}

\begin{abstract}
The chemical behavior of lodine-131 in stack air from this site's Purex process is reported. The radioiodine in the stack gases apparently consists of variable proportions of molecular vapor and other forms of lodine, thus causing the efficiencies for most collection media to vary widely. Activated charcoal is a satisfactory collection medium although Process gases (ammonla and oxides of nitrogen) lower the efficiency of the charcoal from $99 \%$ to $88 \%$. Ambient temperature and humidity had no effect on deposition and retention of lodine in long stainless steel sampling lines. Process conditions did have an effect and estimates of iodine released were $10 \%$ to $15 \%$ low due to this line loss.
\end{abstract}

\section{Introduction}

At the Savannah River Plant, Purex process exhaust gases from the dissolution of irradiated uranium and subsequent chemical separations are released to the atmosphere through a 200-foot-high stack. Stack gases are sampled at the 195-foot level and pass through nearly 300 feet of $1 \frac{1}{2}$-inch-diameter stainless steel pipe to the monitoring station.

Until the summer of 1961, the radioiodine content of stack gases was measured using silver-nitrate impregnated HV-70 filter paper (an asbestos-vegetable fiber paper, silicon coated, used for sampling high humidity air). A continuous-flow caustic scrubber monitored by a single channel gamma spectrometer gave immediate indication of unusual releases. Agreement between these two systems had been good, but at this time became poor. It was evident that process changes had altered the form of iodine present, with resulting lower and variable efficiencies of the monitoring systems. 
A comprehensive program was initiated to study (1) effect of physicochemical behavior of iodine on sampling efficiency, (2) collection media for iodine, (3) deposition of iodine in long sampling lines, and (4) iodine behavior due to variations in the composition of Purex off-gases.

\section{Discussion}

\section{Efficiency Studies}

Silver nitrate papers were considered to have a collection efficiency for iodine of 90 per cent. This was based on laboratory tests over a five-year period and on one plant test in 1956. In 1961, re-evaluation showed that the papers were only 30 per cent efficient for Purex-generated iodine. In the first plant tests, efficiencies were determined by use of sodium hydroxide scrubbers downstream from the silver nitrate paper. Activated charcoal cartridges replaced the scrubbers in subsequent experiments. The last scrubber or cartridge in the series contained negligible amounts of iodine, thus the total system was considered to be 100 per cent efficient. The possibility, although remote, does exist that iodine in some nonreactive, nonadsorbable form did penetrate the entire system.

A known amount of molecular iodine-131 vapor was released into the Purex sampling line during a period of no-iodine releases from the process. The silver nitrate paper collected this molecular iodine with 93 per cent efficiency. These initial studies indicated that the percentage of molecular iodine vapor in the process-generated radioiodine varies considerably, and that other chemical or physical forms of radioiodine are present which do not react rapidly with silver nitrate. 


\section{Collection Media}

The low and variable collection efficiency revealed in preliminary tests of silver nitrate paper prompted a study of other collection media, (see Fig. 1). These materials, with the exception of water scrubbers, were chosen either because they were reported to have high efficiency for molecular iodine removal from air streams or would be expected to show this property. 1,2,3,4

Collection media were evaluated with Purex-generated radioiodine from a sampling line at the 50-foot level of the stack. Some media were also evaluated in the laboratory with molecular iodine which was generated by oxidizing iodine-131 (with $10 \mathrm{mg}$ carrier iodide) with hydrogen peroxide in the presence of phosphoric acid. Materials other than charcoal and filter paper were evaluated by placing about $100 \mathrm{ml}$ of the liquids in gas washing bottles and by placing solids in empty charcoal cartridges. Activated charcoal backups were used to determine efficiency. Glass tubing was used as much as possible for connections between the various pieces of equipment, in order to minimize iodine adsorption by the line. In the laboratory experiments, the filter papers were placed in 3-inch-diameter filter holder assemblies adapted to hold the charcoal cartridge. The process sampling system is described in the Line Loss Studies section. Fig. I compares the results.

All collection media were counted in precalibrated standard geometries on a $3 \times 3$ inch $\mathrm{NaI}(\mathrm{Tl})$ flat surface crystal in conjunction with a 200-channel gamma spectrometer.

Differences in efficiency (Purex process iodine) between collection media may have been due to variations in the amount of molecular iodine. However, charcoal was the only medium whose efficiency was unaffected by the chamical or physical form of the iodine. 
Activated Charcoal

From the efficiency tests we concluded that radioiodine sampling of separations process gases should not be based on iodine chemistry. Numerous studies at other sites ${ }^{1,2,4}$ concerning sampling or removal of iodine from air streams indicate the effectiveness of activated charcoal. Nuclear Safety reviews ${ }^{5,6,7}$ furnish an extensive bibliography in this field.

Because adsorption of gases on activated charcoal and filtration of particulates by high efficiency paper are both physical processes, the sampling system was redesigned with a plain HV-70 paper and three activated charcoal cartridges in series. The first cartridge was changed daily and the first and second backup cartridges were changed weekly.

Routine 24-hour samples were drawn from the 195-foot sampling line, while in concurrent tests, samples were drawn from the 50-foot sampling line (Fig. 2). The charcoal was more than 99 per cent efficient at linear flow rates from 59 to $103 \mathrm{ft} / \mathrm{min}$ for tests up to three hours' duration. Tests running 16 to 24 hours indicated efficiencies of 75 to 95 per cent. Average efficiencies of routine charcoal cartridges measuring Purex-generated iodine under all stack gas conditions are shown in Fig. 3. Penetration of radioiodine in the charcoal cartridge was observed by measuring back-to-front counting ratios. These ratios, or penetration factors, are shown in Fig. 4.

Fig. 3 and 4 indicate that nitrogen oxides affect charcoal performance. This effect was also noted in a different separations process stack when efficiencies decreased and penetration factors increased as large amounts of nitrogen oxides were released to a previously clean air stream. The effect of $\mathrm{NO}_{2}$ is dependent on its concentration and the sampling time; short tests showed no effect, longer tests showed an appreciable effect. This may indicate that $\mathrm{NO}_{2}$ gradually displaces iodine adsorbed on the charcoal. It does not appear that a reaction between $\mathrm{NO}_{2}$ and $\mathrm{I}_{2}$ takes place in the stack air to form less readily adsorbed compounds because the decreased efficiency was not noted in short term tests. 
The temperature rise in the charcoal bed due to heat of adsorption of stack gases was evaluated. Nitrogen dioxide, generated in the laboratory by reacting copper with concentrated nitric acid, was passed through the bed and the temperature measured. The extent of the reaction depended on $\mathrm{NO}_{2}$ concentration and flow rate of the air stream. Measurements in the plant showed a maximum temperature rise of $5^{\circ} \mathrm{C}$.

\section{Line Loss Studies}

Deposition of molecular iodine on surfaces has been observed by numerous works; ${ }^{2,8,9,10,11}$ its adsorption and retention in long sampling lines at SRP caused estimates of iodine released to be $10 \%$ to $15 \%$ low.

The Purex process stack and associated sampling lines is shown in Fig. 2. The sampling line from the 50-foot elevation was used for line-loss experiments. A scaffold was constructed and a sampling station installed where the line enters the stack. The other station and the routine sampling equipment for the line from the 195-foot elevation were located in the Fan Building. Samplers 1ocated at points $A$ and $C$ were airtight stainless steel boxes with three compartments in series, each with a threaded hole designed. to hold the charcoal cartridge. A filter-paper sampling box was also located at point $\mathrm{C}$. A series of three charcoal cartridges at points $A$ and $C$ were used to sample the stack air during line-loss tests. Flow rates were maintained equal at both sampling stations throughout the test. In order to purge the line with clean air, a blank was inserted in the indicated flange and the removable pipe section was disconnected.

After the line was purged with clean air for 16 hours, a series of samples of stack air were simultaneously collected at points $A$ and $C$ at known flow rates. Comparison of iodine concentrations at the two points showed the apparent loss for that length of line. The purging reduced the concentration of iodine in the air to the extent that it contributed less than one per cent of the concentrations observed in subsequent line loss tests. Fig. 5 shows typical 
line losses in the presence of nitrogen oxides. These losses averaged 14 per cent during the first test interval ( $15 \mathrm{~min}$ ) and decreased in subsequent ( $15 \mathrm{~min}$ ) intervals to less than 5 per cent. Other tests showed that when the concentration of $\mathrm{NO}_{2}$ in the air increased, the desorption rate of iodine also increased, causing lower apparent line loss.

When ammonia, a process off-gas, was present to react with nitrogen oxides to form $\mathrm{NH}_{4} \mathrm{NO}_{3}$, greater line loss was noticed (Fig. 6). Under these conditions, loss for the first test interval averaged 31 per cent and decreased slowly in subsequent intervals. Fig. 7 shows line loss during changing stack conditions. Line loss in the presence of $\mathrm{NO}_{2}$ is represented in test interval 1 through 5. At this point, ammonia gas was exhausted into the stack and line loss increased abruptly. Iine losses could not be correlated with temperature or humidity in any test. Sampling lines were purged with clean air between each series to allow previously deposited iodine to bleed-off or desorb. Fig. 8 shows a typical bleed-off curve.

The difference, expressed as $\mu c$ collected, between points $A$ and C represented the apparent amount of iodine deposited for a given test. The cumulative amount of iodine deposited in the line loss test series was $0.2282 \mu \mathrm{c}$. A total of $0.2168 \mu \mathrm{c}$ was desorbed from the line in purging test series which followed each line loss series. This indicates an agreement to within 5 per cent between jodine apparently deposited in the line and that subsequently removed by purging.

As shown in Fig. 5, average apparent line loss in the presence of $\mathrm{NO}_{2}$ would be close to zero for a daily sample. Fig. 6 indicates, however, that if the $\mathrm{NO}_{2}$ content of the air is minimized, the average apparent loss would be 24 per cent. Using dissolving schedules to estimate a typical Purex sampling day, 10 to 15 percent average line loss seems reasonable. 


\section{Condensation Nuclei}

Chamberlain and wiffen ${ }^{12}$ reported on the behavior of trace quantities of iodine in air streams. In the presence of large amounts of condensation nuclei $\left(20,000 / \mathrm{cm}^{3}\right)$, iodine activity did not deposit on surfaces as it did when nuclei concentration was less than $100 / \mathrm{cm}^{3}$. The iodine, possibly adsorbed on the nuclei, passed through filter paper, but was efficiently adsorbed by activated charcoal. Condensation nuclei range from 0.001 to 0.1 micron in diameter. A study of the KAPL separations process ${ }^{13}$ revealed that the mean particle size in their stack air is 0.05 micron. Because greater than 99 per cent of the iodine released in the SRP Purex stack has passed through an efficient particle filtration system, condensation nuclei, if present, would represent the largest percentage of particles in the air. Measurements with plain filter paper showed the iodine to be less than one per cent associated with filterable particles.

Condensation nuclei may explain, at least in part, the behavior of iodine in SRP Separations stacks, because efficiencies of various sampling media (except activated charcoal) were lower for Purex iodine than for molecular iodine.

\section{lodine Compounds}

Although the presence of condensation nuclei seems likely, nonreactive iodine compounds may exist in our stack air streams. C. W. Sill ${ }^{4}$ at NRTS, Idaho, observed considerable differences in caustic-thiosulfate scrubber efficiencies for iodine generated by different methods. His scrubbers were 98 per cent efficient for iodine from a ruptured fuel element in a reactor; an improved scrubber was 99.9 per cent efficient for laboratory-generated iodine vapor, but only 30 per cent efficient for iodine in a separations process off-gas system. Sill postulated the possible formation of compounds such as $\mathrm{NOI}$ and $\mathrm{NO}_{2} I$ which could cause a decrease in reactivity with the thiosulfate solution. 
Kahn and Wahl $^{14}$ examined the chemical behavior of iodine at low concentrations. In oxidation processes low concentrations of iodine $\left(10^{-7}\right.$ molar, or less) did not behave as did higher concentrations. In addition to iodine and iodate fractions from the oxidation of iodide, three fractions, which defied characterization, were isolated. Kahn and Wahl postulated the formation of intermediate, reactive oxidation states such as $\mathrm{HIO}$ or $\mathrm{HIO}_{2}$ which reacted with trace impurities.

Since acidic oxidizing conditions are present at various locations in the process, there may be iodine reactions similar to those described. Such compounds would be less reactive than iodine vapor and thus show decreased affinity for chemical collectors and decreased tendency to deposit in sampling lines.

\section{Conclusions}

As a result of our studies, it is believed that molecular $I_{2}$, the effect of condensation nuclei, and the presence of intermediate compounds may all affect collection efficiency and line loss. Some useful conclusions can be drawn about iodine sampling, no matter which explanation of iodine behavior is accepted:

$\diamond$ If molecular I2 vapor is sampled, various scrubber solutions, filters, or solid materials may be used with consistently good collection efficiencies.

$\diamond$ If the chemical or physical form of the iodine is not known, the best collection medium is a combination of high efficiency filter paper and activated carbon. Charcoal efficiencies of 88 per cent were observed at SRP in the presence of Purex gases, and 99 per cent in their absence.

$\diamond$ Molecular $I_{2}$ vapor deposits in long sampling lines. Zero to 31 per cent was deposited at SRP, under varying process conditions. 
$\diamond$ Nitrogen oxides minimize the line loss phenomenon, but eventually cause some desorption of iodine from activated charcoal. This desorption caused higher penetration factors and lowered the collection efficiencies at SRP.

\section{Acknowledgment}

The information in this article was developed during the course of work under Contract AT(07-2)-I with the U. S. Atomic Energy Commission. 


\section{References}

1. G. K. Cederberg, and D. K. Macqueen, USAEC Report IDO-14566 (1961).

2. A. R. Bancroft, L. C. Watson, and R. Hewitt, AECL Report CRCE-98I (1960).

3. S. Kitani, and H. Ezure, J. Atomic Energy Soc. Japan 3, 787-791 (1961).

4. C. W. Sill, and J. K. Flygare, Health Physics 2, 261-268 (1960).

5. USAEC Review "Nuclear Safety" 1, 40-46 (Mar. 1960).

6. USAEC Review "Nuclear Safety" 2, 35-38 (Mar. 1961).

7. USAEC Review "Nuclear Safety" 3, 41-44 (Mar. 1962).

8. J. B. Morris, H. R. Diffey, B. Nicholls, and C. H. Rumary, Reactor Sci. and Tech. 16, 437-445 (1962).

9. W. J. Megaw, and F. G. May, Reactor Sci. and Tech. 16, 427-436 (1962).

10. USAEC Review "Nuclear Safety" 3, 46-49 (Dec. 1961).

11. M. No Meyers, USAF and USAEC Report APEX-617 (1961).

12. A. C. Chamberlain, and R. D. Wiffen, Geofisica pura e applicata 42, 42-48 (1959).

13. J. J. Fitzgerald, USAEC Report KAPL-1015 (1954).

14. M. Kahn, and A. C. Wahl, J. Chem. Phys. 2l, 1185-1189 (1953).

15. A. C. Chamberlain, A. E. J. Eggleton, W. J. Megaw, and J. B. Morris, UKAEA Report AERE-R-34l2 (1960).

16. USAEC Review "Nuclear Safety" 2, 39-41 (June 1961). 


\section{Figures}

Fig. I. Collection Efficiency, per cent

Fig. 2. Separations Stack Monitoring System

Fig. 3. Charcoal Efficiencies for Purex lodine (24-hour samples)

Fig. 4. Penetration Factors for Charcoal Cartridges

Fig. 5. lodine Line Loss in Presence of $\mathrm{NO}_{2}$

Fig. 6. lodine Line Loss in Presence of $\mathrm{NH}_{4} \mathrm{NO}_{3}$

Fig. 7. Line Loss in Presence of $\mathrm{NO}_{2}$ Through Interval 5, then $\mathrm{NH}_{4} \mathrm{NO}_{3}$

Fig. 8. Typical Bleed-Off Curve 
Fig. I. Callection Efficiency, per cent

\begin{tabular}{|c|c|c|}
\hline Sampling Media & $\begin{array}{c}\text { Molecular lodine } \\
\text { (Laboratory) }\end{array}$ & $\begin{array}{c}\text { Process lodine } \\
\text { (Purex }-15 \text { min. tests) }\end{array}$ \\
\hline Activated Charcoal ** & $>99$ & $>99$ \\
\hline Silica Gel & * & 78 \\
\hline IM NaOH $-0.1 \mathrm{M} \mathrm{Na}{ }_{2} \mathrm{~S}_{2} \mathrm{O}_{3}$ & 93 & 59 \\
\hline $0.1 \mathrm{M} \mathrm{NaOH}$ & 92 & 56 \\
\hline KI (Solution) & * & 44 \\
\hline $\mathrm{AgNO}_{3}$ Crystals & * & 35 \\
\hline Water & * & 30 \\
\hline 4A Molecular Sieve & * & 28 \\
\hline Fiberglass $\mathrm{AgNO}_{3}$ Paper $^{\dagger}$ & * & 31 \\
\hline $\mathrm{HV}-70 \mathrm{AgNO}_{3}$ Paper $^{\dagger}$ & 90 & 30 \\
\hline Ag-Plated Copper & * & 24 \\
\hline Cu Turnings & * & 11 \\
\hline \multicolumn{3}{|c|}{$\begin{array}{l}\text { * Not evaluated. } \\
\text { ** Permissible Cartridge for Organic Vapors, manufactured by Mine } \\
\text { Safety Appliances Co., containing } 70 c c \text { of } 8-14 \text { mesh, medium } \\
\text { hard, activated coconut shell carbon. } \\
+ \text { Gelman Instrument Co., Chelsea, Michigan. }\end{array}$} \\
\hline
\end{tabular}




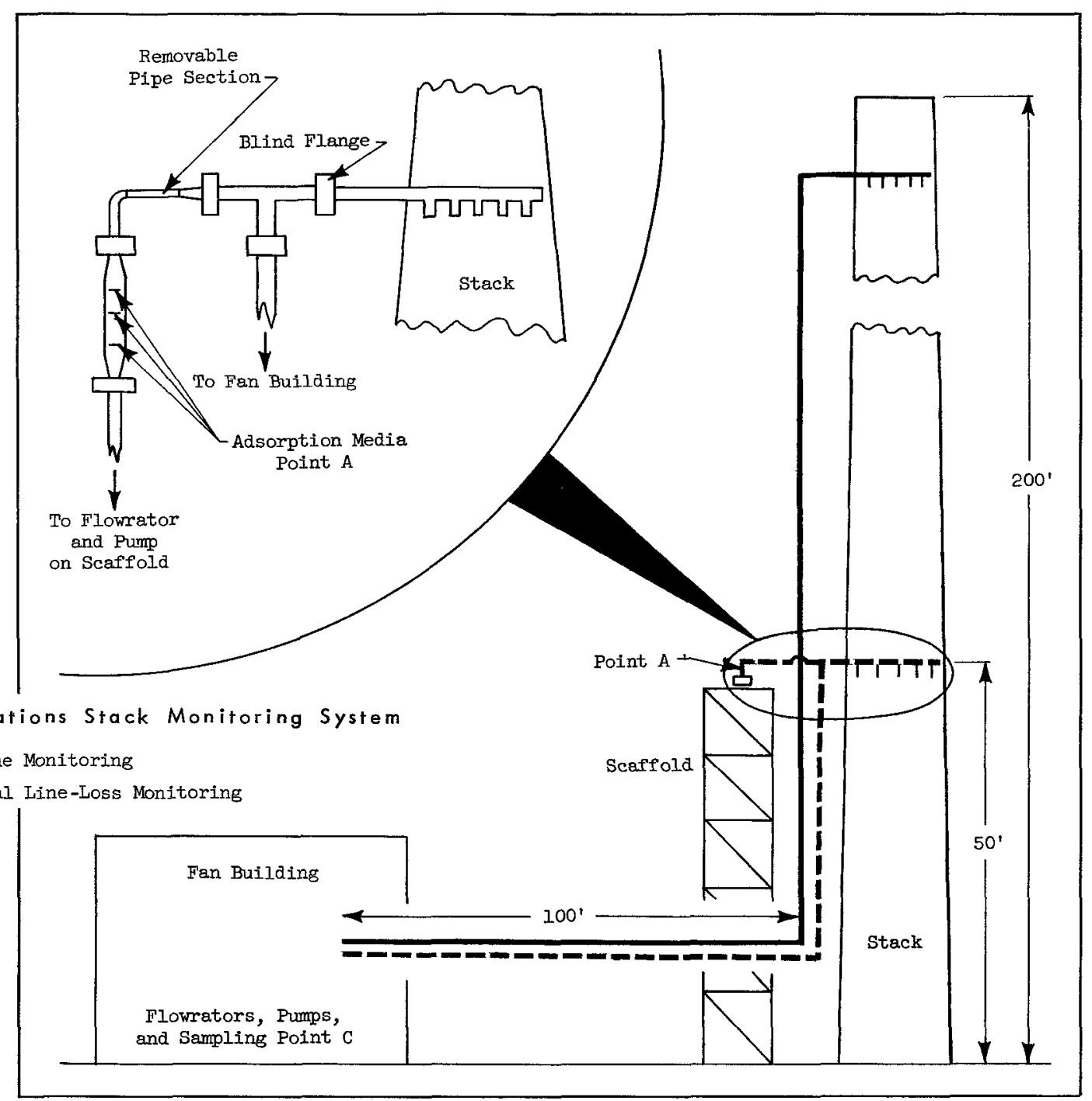


Fig. 3. Charcoal Efficiencies for Purex lodine (24-hour samples)

\begin{tabular}{|c|c|c|}
\hline Stack Gases Present & No. of Samples & Avg. Efficiency \\
\hline $\mathrm{NO}_{2}, \mathrm{NH}_{3}{ }^{*}, \mathrm{NH}_{4} \mathrm{NO}_{3}$ & 84 & 88.0 \\
\hline $\mathrm{NO}_{2}$ & 14 & 88.5 \\
\hline None & 7 & 99.0 \\
\hline
\end{tabular}

* $\mathrm{NH}_{3}$ and $\mathrm{NH}_{4} \mathrm{NO}_{3}$ were present at various times due to aluminum jacket dissolution.

Fig. 4. Penetration Factors for Charcoal Cartridges* lodine Source

Average Penetration Factor

Standard**

0.70

Purex, 3 hr. sample

0.70

Purex, $24 \mathrm{hr}$. sample

0.82

Purex, $168 \mathrm{hr}$. sample (Ist backup to daily)

0.92

Purex, $168 \mathrm{hr}$. sample (2nd backup to daily)

0.96

* Purex stack samples were taken during a 3-month period and represent charcoal behavior with average $\mathrm{NO}_{2}$ concentrations.

** Standards are prepared with a known amount of $|-| 3 \mid$ on the surface layer of charcoal. 


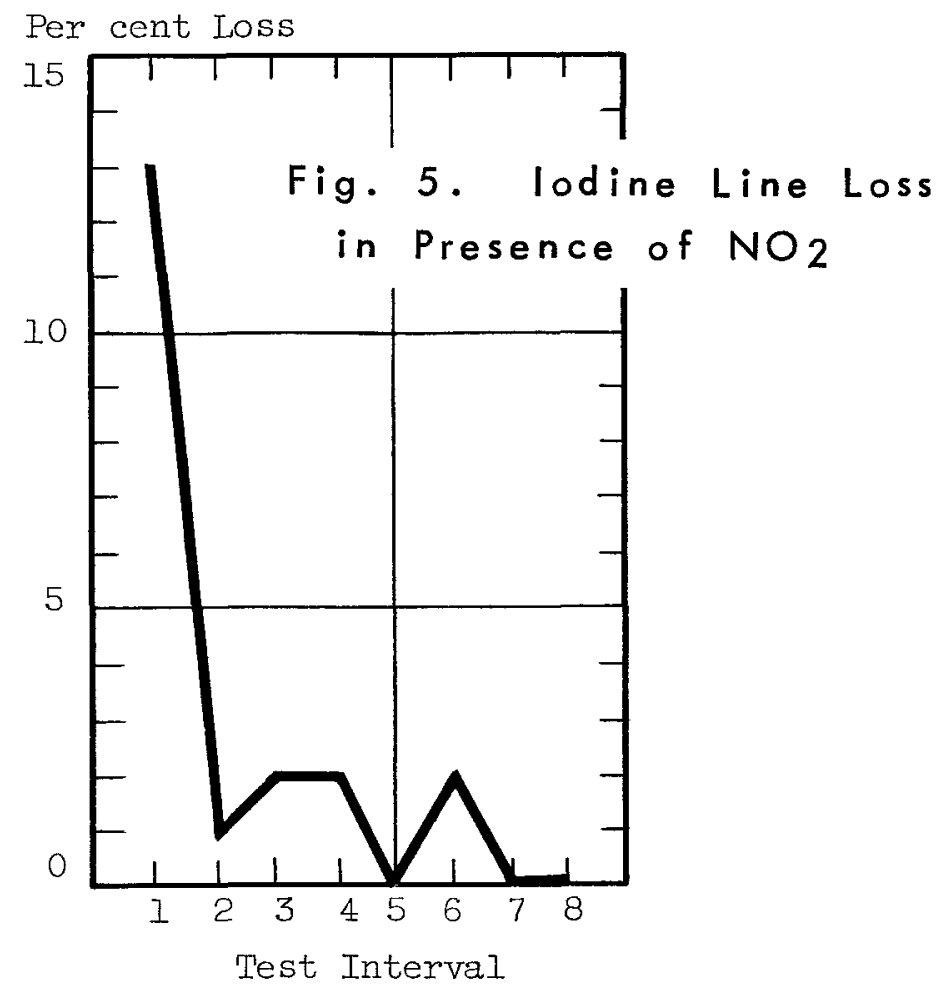

Elapsed Time $2 \mathrm{hr} 20 \mathrm{~min}$

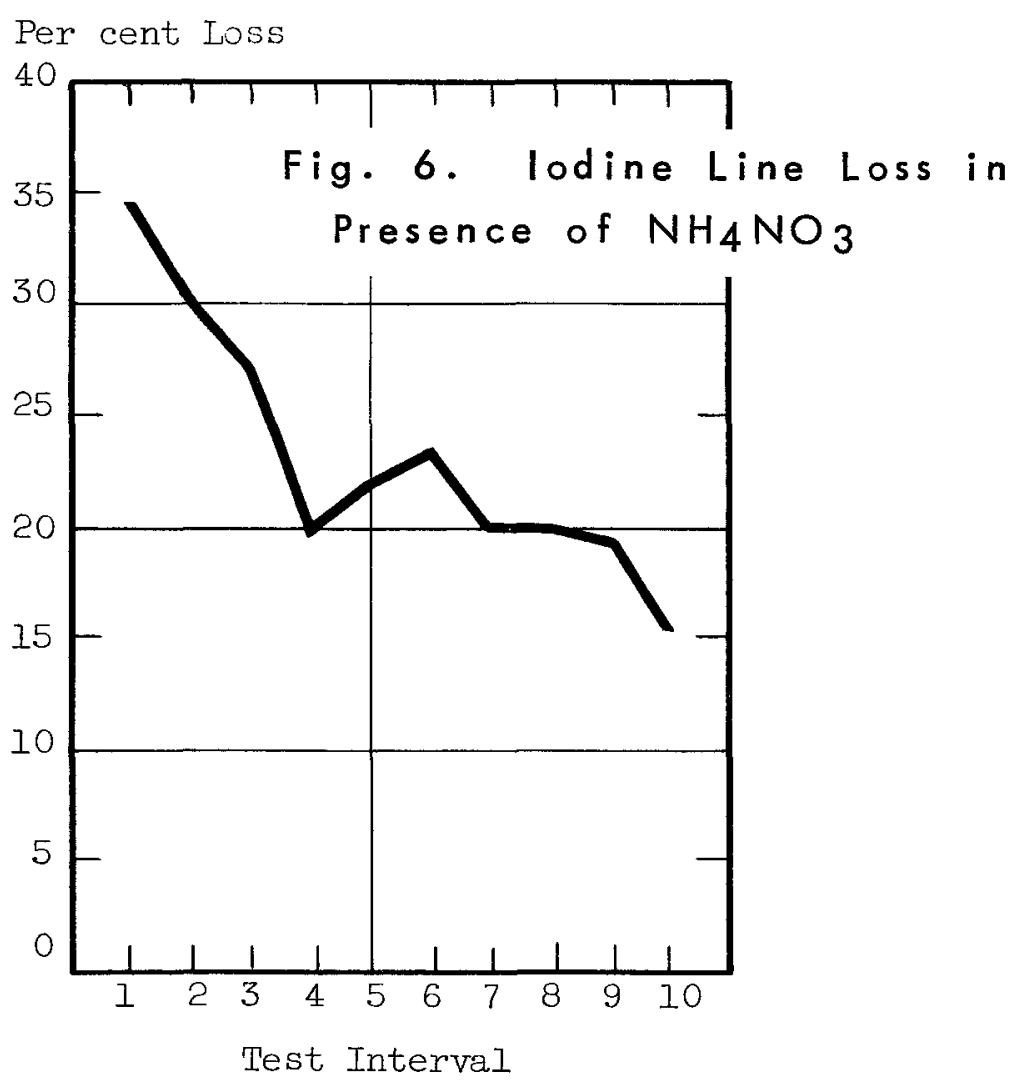

Elapsed Time $4 \mathrm{hr} 30 \mathrm{~min}$ 


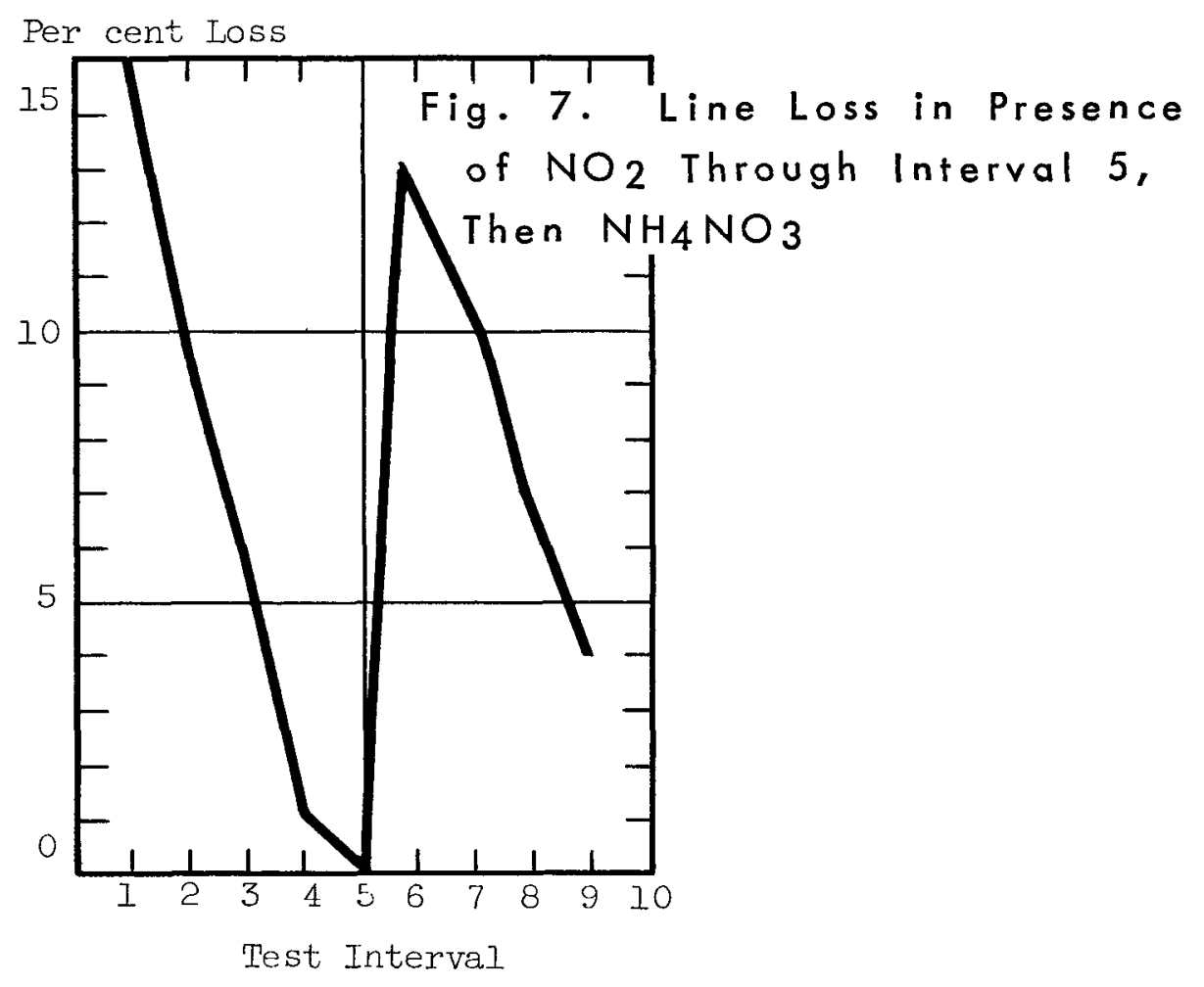

Elapsed Time $5 \mathrm{hr}$

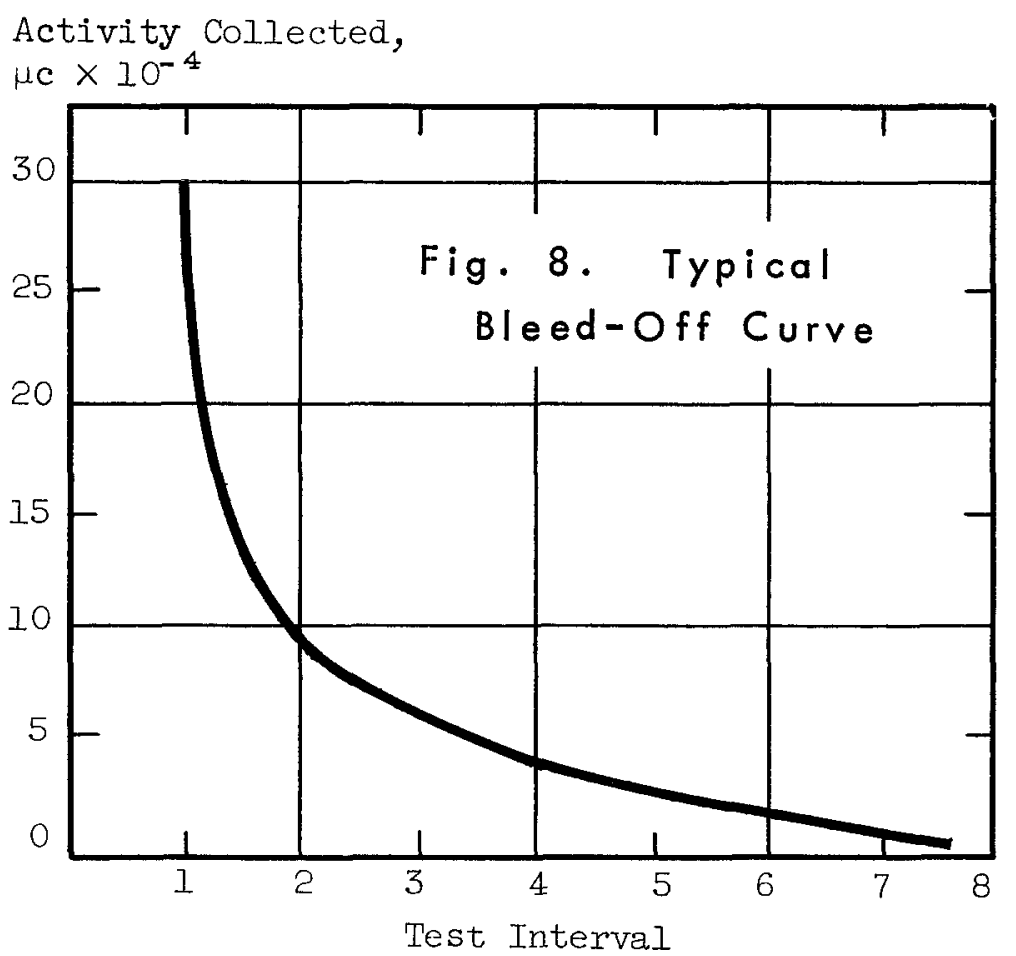

Elapsed Time $2 \mathrm{hr}$ 